\title{
Article
}

\section{Metal-Ligand Cooperation Facilitates Bond Activation and Catalytic Hydrogenation with Zinc Pincer Complexes}

Michael Rauch, Sayan Kar, Amit Kumar, Liat Avram, Linda J.W. Shimon, and David Milstein

J. Am. Chem. Soc., Just Accepted Manuscript • Publication Date (Web): 28 Jul 2020

Downloaded from pubs.acs.org on July 29, 2020

\section{Just Accepted}

"Just Accepted" manuscripts have been peer-reviewed and accepted for publication. They are posted online prior to technical editing, formatting for publication and author proofing. The American Chemical Society provides "Just Accepted" as a service to the research community to expedite the dissemination of scientific material as soon as possible after acceptance. "Just Accepted" manuscripts appear in full in PDF format accompanied by an HTML abstract. "Just Accepted" manuscripts have been fully peer reviewed, but should not be considered the official version of record. They are citable by the Digital Object Identifier (DOI®). "Just Accepted" is an optional service offered to authors. Therefore, the "Just Accepted" Web site may not include all articles that will be published in the journal. After a manuscript is technically edited and formatted, it will be removed from the "Just Accepted" Web site and published as an ASAP article. Note that technical editing may introduce minor changes to the manuscript text and/or graphics which could affect content, and all legal disclaimers and ethical guidelines that apply to the journal pertain. ACS cannot be held responsible for errors or consequences arising from the use of information contained in these "Just Accepted" manuscripts. 


\section{INTRODUCTION}

In moving towards a more sustainable future, it is imperative to develop "green" chemical transformations that are both economical and free of waste generation. ${ }^{1}$ The most successful metals employed in catalytic reactions have historically been the noble metals, which typically suffer from high price, low abundance and toxicity. ${ }^{2}$ Thus, in the past two decades, there has been a notable increase in efforts to develop both organocatalysts and catalysts based on main group metals, which are generally more abundant and cost effective alternatives to the noble metals. ${ }^{2-4}$ Furthermore, significant effort has focused on developing transformations that are atom-efficient or generate byproducts that are benign or useful in their own right (e.g. $\mathrm{H}_{2} \mathrm{O}$ and $\mathrm{H}_{2}$ ). ${ }^{5}$

With respect to utilizing molecular main group metal complexes for catalytic transformations, one common impediment is redox innocence, often nullifying their ability to undergo the fundamental organometallic reactions of oxidative addition and reductive elimination (Figure 1) ${ }^{3,6}$ For example, in homogeneous zinc, magnesium and calcium catalyzed reactions, the metal is almost exclusively limited to the $\mathrm{M}^{2+}$ oxidation state, and thus productive cycles depend on only sigma bond metathesis and/or insertion steps which do not alter the oxidation state of the metal. ${ }^{2,4}$ Nonetheless, utilizing this paradigm, complexes of these metals and other main group metals have demonstrated versatile catalytic applications including hydroamination, ${ }^{7}$ polymerization, ${ }^{8}$ hydrosilylation, ${ }^{9-12}$ hydroboration $^{12}$ and hydrogenation ${ }^{13-17}$ in which metal hydride intermediates are often speculated (and occasionally isolated). ${ }^{18-20} \mathrm{Zinc}$, in particular, has shown activity for all of these transformations, and is a promising metal due to its low cost, relatively high abundance and low toxicity. ${ }^{2,21,22}$

Our group is interested in leveraging metal-ligand cooperation (MLC), in which bond activation occurs across both metal and ligand, to effect transformations in an atom-economical, waste-free fashion. ${ }^{23}$ The MLC approach has long been demonstrated for advancements with the noble metals, and more recently with more abundant first row transition metals, for reversible bond activation resembling oxidative addition and reductive elimination (Figure 1). ${ }^{1,24-27}$ Importantly, the metal center does not change oxidation state in this process, and as a result, this activation mode could also be potentially operative with redox-innocent main group metals. ${ }^{28}$

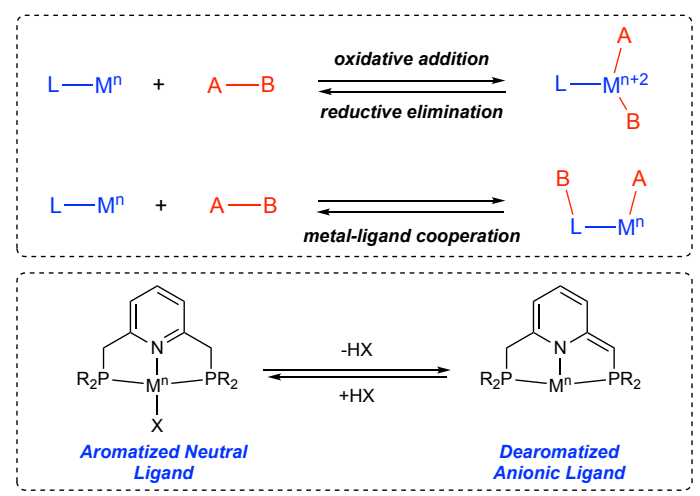

Figure 1. Top: Bond activation via oxidative addition/reductive elimination compared to bond activation by metal-ligand cooperation. Bottom: Nominal coordination modes of the $\mathrm{PNP}^{\mathrm{R}}$ ligand to a generic metal $(M)$ in which the ligand is an aromatized $\left(\mathrm{L}_{3}\right)$ neutral ligand versus a dearomatized $\left(\mathrm{L}_{2} \mathrm{X}\right)$ anionic ligand.

With respect to aromatization/dearomatization MLC with main group metals, Braunstein, Danopoulos and co-workers characterized a family of dearomatized lithium and potassium complexes, but bond activation with these complexes has not yet been demonstrated. ${ }^{29}$ Most notably, Berben and co-workers have shown that aluminum complexes supported by a tridentate bis(imino)pyridine ligand can activate $\mathrm{N}-\mathrm{H}$ and $\mathrm{O}-\mathrm{H}$ bonds across the aluminum center and ligand. ${ }^{30-32}$ Other examples with Group 13 metals have also been introduced and explored with similar application. ${ }^{33}$ In the case of zinc, we are only aware of reports in which the ligand itself is implicated as a proton or electron reservoir, ${ }^{34,35}$ and very recently, 
MLC was proposed to facilitate methanol activation en route to a characterized zinc methylcarbonate species in a novel $\mathrm{CO}_{2}$ reduction process. ${ }^{36}$ Nonetheless, direct observation of reversible $\mathrm{H}-\mathrm{X}$ bond activation across any main group metal and ligand via aromatization/dearomatization is unknown, and main group metal-ligand cooperation remains an underexplored area.

Based on our previous efforts, we hypothesized that it should be possible to synthesize pincer complexes of main group metals, such as zinc, that could reversibly activate bonds by MLC in which the oxidation state of the metal remains unchanged. If so, zinc-ligand cooperation could be employed to catalyze useful transformations, such as (de)hydrogenation reactions, which typically occur at a transition metal center. Herein, we establish that both aromatized and dearomatized zinc complexes supported by the PNP ligand (Figure 1) can be prepared and isolated in a straightforward manner. We demonstrate the ability of this system to heterolytically cleave and form $\mathrm{H}-\mathrm{H}$ and N-H bonds. Finally, this new mode of bond activation by zinc is applied towards the additive-free, catalytic hydrogenation of imines and ketones.

\section{RESULTS AND DISCUSSION}

Access to a dearomatized zinc pincer complex is readily achieved via the reaction of the $\mathrm{PNP}^{\mathrm{tBu}}$ pro-ligand with dimethylzinc at $140^{\circ} \mathrm{C}$ in toluene to generate $\mathrm{PNP}^{\mathrm{tBu} *} \mathrm{ZnMe}(\mathbf{1})$ concurrent with loss of methane (Scheme 1). This simultaneous deprotonation and complexation approach is analogous to the procedure employed to prepare lithium and potassium pincer complexes, ${ }^{29}$ and is not uncommon in the synthesis of zinc alkyl and amido species. ${ }^{8,37,38}$ In contrast to procedures employed in the preparation of traditional dearomatized transition-metal pincer complexes, ${ }^{24}$ in this approach, the addition of base is obviated by the basic nature of dimethylzinc itself, which is capable of deprotonating the side arm of the ligand. Upon mixing, the colorless ligand and dimethylzinc starting materials form a bright yellow solution, which upon heating evolves gas and exhibits an orange/red color, atypical of $\mathrm{Zn}^{2+}$ compounds but quite typical of dearomatized PNP pincer complexes. ${ }^{29}$ From monitoring the reaction progress with ${ }^{1} \mathrm{H}$ and ${ }^{31} \mathrm{P}\left\{{ }^{1} \mathrm{H}\right\}$ NMR spectroscopy, we propose that the room temperature yellow intermediate is formed by coordination of the $\mathrm{PNP}^{\mathrm{tBu}}$ ligand to $\mathrm{ZnMe}_{2}$, and subsequent heating results in the loss of methane and formation of the orange/red complex 1 (see Supporting Information). The dearomatized compound, $\mathrm{PNP}^{\mathrm{B} \mathrm{Bu} *} \mathrm{ZnMe}$, exhibits several characteristic signals in solution by NMR spectroscopy. For example, in toluene- $\mathrm{d}_{8}$, multiplets at $-0.02 \mathrm{ppm}$ in the ${ }^{1} \mathrm{H}$ NMR spectrum and $3.47 \mathrm{ppm}$ in the ${ }^{13} \mathrm{C}\left\{{ }^{1} \mathrm{H}\right\}$ NMR spectrum indicate the presence of a zinc methyl moiety coupled to two inequivalent phosphorus atoms. In addition, the inequivalent arms of the pincer ligand are distinguishable by both ${ }^{1} \mathrm{H}$ (doublet at $3.53 \mathrm{ppm}$ and broad singlet at $2.62 \mathrm{ppm}$ ) and ${ }^{13} \mathrm{C}\left\{{ }^{1} \mathrm{H}\right\}$ (doublet at $57.43 \mathrm{ppm}$ and doublet of doublets at $31.19 \mathrm{ppm}$ ) NMR spectra, associated with the deprotonated and protonated arms, respectively, as confirmed by HSQC and DEPTQ NMR experiments. Most evidently, the ${ }^{31} \mathrm{P}\left\{{ }^{1} \mathrm{H}\right\}$ NMR of 1 exhibits two distinct doublets (40.75 ppm and $5.74 \mathrm{ppm}$ ), with $\mathrm{J}_{\mathrm{PP}}$ coupling constants of $18 \mathrm{~Hz}$, indicative of the inequivalent phosphorus atoms, with similar shifts as the known lithium and potassium compounds. ${ }^{29}$

Utilizing the same protocol, a dearomatized zinc ethyl compound, $\mathrm{PNP}^{\mathrm{tBu} *} \mathrm{ZnEt}$ (2), was also prepared (Scheme 1). The zinc ethyl complex forms via a similar pathway, and its spectroscopic features essentially match that of $\mathbf{1}$ (see Supporting Information Table S2). Most diagnostically, the ${ }^{31} \mathrm{P}\left\{{ }^{1} \mathrm{H}\right\}$ NMR also exhibits two doublets $\left(39.13 \mathrm{ppm}\right.$ and $\left.4.53 \mathrm{ppm} ; \mathrm{J}_{\mathrm{pp}}=15 \mathrm{~Hz}\right)$. The zinc amido complex, $\mathrm{PNP}^{\mathrm{tBu}} \mathrm{ZnN}\left(\mathrm{SiMe}_{3}\right)_{2}(4)$, is also isolable, and is prepared via the reaction of $\mathrm{PNP}^{\mathrm{tBu}} \mathrm{ZnCl}_{2}$ (3) (see Supporting Information for preparation and characterization of 3 ) with two equivalents of sodium bis(trimethylsilyl)amide (Scheme 1). As compared to $\mathbf{1}$ and 2, $\mathrm{PNP}^{\mathrm{tBu} *} \mathrm{ZnN}\left(\mathrm{SiMe}_{3}\right)_{2}$ (4) also exhibits two resonances in the ${ }^{31} \mathrm{P}\left\{{ }^{1} \mathrm{H}\right\}$ NMR (35.20 ppm and $-0.33 \mathrm{ppm}$ ), but unlike those of the corresponding methyl and ethyl derivatives, the peaks are singlets indicating no observable P-P coupling across the zinc center.

\section{Scheme 1. Synthesis of Zinc Pincer Complexes}

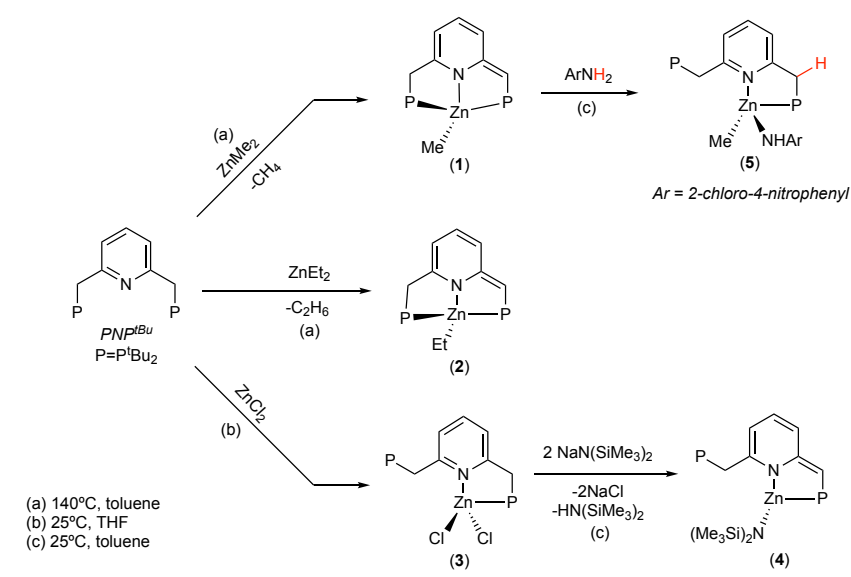

Single crystals of $\mathrm{PNP}^{\mathrm{tBu} * \mathrm{ZnR}}(\mathrm{R}=\mathrm{Me}, \mathrm{Et})$ and $\mathrm{PNP}^{\mathrm{t}}$ ${ }^{\mathrm{Bu} *} \mathrm{ZnN}\left(\mathrm{SiMe}_{3}\right)_{2}$ were grown by cooling saturated pentane solutions to $-32^{\circ} \mathrm{C}$, and the molecular structures were determined by $\mathrm{X}$ ray crystallography (Figure 2), confirming the formation of a monomeric, dearomatized zinc pincer complex in each case. The zinc center in $\mathbf{1}$ and $\mathbf{2}$ is pseudotetrahedral, distorting the PNP ligand quite substantially from its typically planar conformation. Supporting the spectroscopic data, conclusive evidence of the dearomatized nature of the ligand is clear in each case: $(i)$ the hydrogen atoms on the pincer arms were found and refined, and (ii) the C-C distances are indicative of double bond character on one of the arms and single bond character on the other arm (see Figure 2 and Supporting Information Table S1). Also in agreement with the spectroscopic data, the $\mathrm{Zn}-\mathrm{P}$ distance of the ligand arm that remains protonated increases $1<2<<4$ (2.675, $2.965 \AA$ and $4.914 \AA$, respectively); in the case of 3 , the second phosphorus arm is clearly unbound in the solid state, rendering the zinc center three-coordinate. As such, it is understandable that the ${ }^{31} \mathrm{P}\left\{{ }^{1} \mathrm{H}\right\}$ NMR spectrum of $\mathbf{1}$ and $\mathbf{2}$ exhibit two doublets (from P-P coupling), whereas that for $\mathbf{4}$ exhibits two singlets, indicating an open arm in solution. Though a coordination number of four is common for zinc, three-coordinate zinc is less common but has been observed. ${ }^{39}$

While the preparation of organozinc ( $\mathrm{RZnX})$ species is formally an oxidative addition of an organic $\mathrm{RX}$ to $\mathrm{Zn}^{0}$, these species are typically stoichiometric reagents; ${ }^{40}$ thus, in moving towards catalytic applications, the development of molecular and recyclable zinc compounds that can perform bond activation is significant. We previously reported the activation of $\mathrm{N}-\mathrm{H}$ bonds mediated by MLC with a dearomatized ruthenium complex. ${ }^{41,42} \mathrm{We}$ found that electron-deficient aniline derivatives reacted via aromatization/dearomatization MLC to afford ruthenium anilido complexes 
(1)
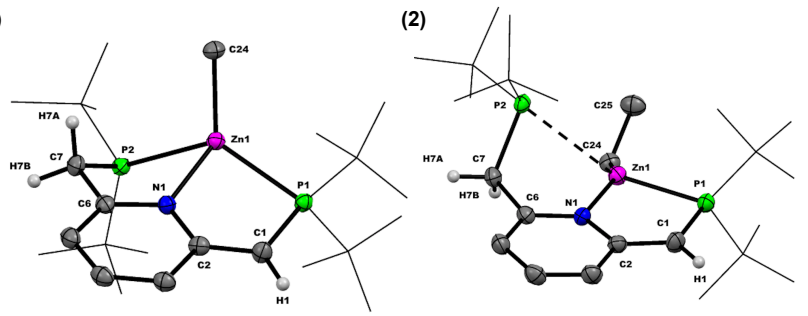

(4)

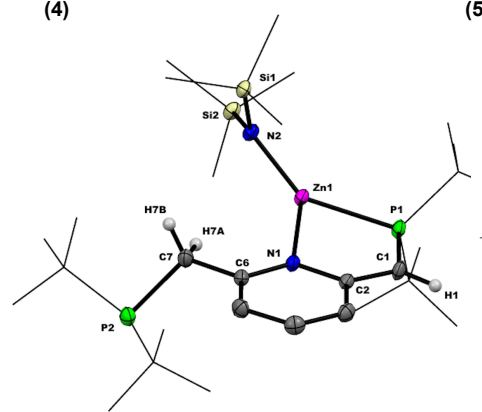

(5)

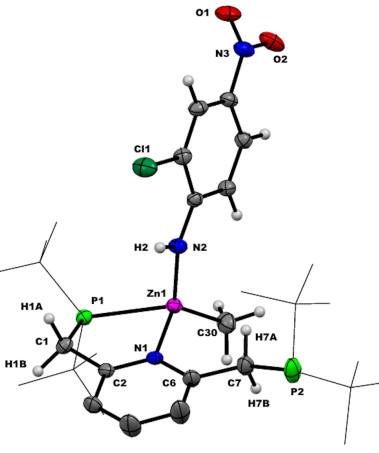

Figure 2. Molecular structures of complexes (1), (2), (4) and (5). Selected hydrogen atoms omitted for clarity. Some groups displayed as wireframe for clarity. Select bond lengths $(\AA)$ and angles $\left(^{\circ}\right)$ : (1): Zn1-C24 1.9969(18), Zn1-P1 2.4252(5), Zn1-P2 2.6750(5), P2-C7 1.8646(18), C7-C6 1.510(3), P1-C1 1.7608(18), C1-C2 1.387(2). (2): Zn1-C24 1.9731(14), Zn1-P1 2.4267(4), Zn1-P2 2.965, P1-C1 1.7491(15), C1-C2 1.394(2), P2C7 1.8684(14), C7-C6 1.5043(19), N1-Zn1-P1 85.36(3). (4): Zn1-N2 1.8849(18), Zn1-P1 2.3369(6), Zn1-P2 4.914, P1-C1 1.746(2), C1-C2 1.402(3), P2-C7 1.866(2), C7-C6 1.508(3), P1Zn1-N1 87.56(5), N1-Zn1-N2 127.36(7). (5): Zn1-N2 1.9954(14), Zn1-P1 2.4606(4), Zn1-C30 1.9872(18), P1-C1 1.8367(17), C1-C2 1.509(2), P2-C7 1.8648(18), C7-C6 1.510(2). See Supporting Information for molecular structure of (3).

irreversibly. In the case of ammonia, aniline and other amines, reversible addition was observed. Related palladium and copper chemistry has also been explored. ${ }^{43}$ We began our reactivity studies with the room temperature addition of the electron-poor aniline derivative, $\mathrm{H}_{2} \mathrm{NAr}$ ( $\mathrm{Ar}=$ 2-chloro-4-nitrophenyl), to 1, which resulted in the immediate formation of the aromatized complex, $\mathrm{PNP}^{\mathrm{tBu}} \mathrm{Zn}(\mathrm{Me}) \mathrm{NHAr}(\mathbf{5})$, in which $\mathrm{N}-\mathrm{H}$ activation has occurred across both the metal center and the ligand side-arm (Scheme 1). ${ }^{44}$ Notably, the oxidation state of the zinc center remains +2 , in that the pincer ligand itself reassumes a neutral charge, with both the methyl and anilido moieties serving as X-type ligands. ${ }^{45} \mathrm{In}$ solution, NMR spectroscopy provides conclusive evidence of the formation of $\mathbf{5}$, indicating symmetrization of the pincer side arms. Specifically, the ${ }^{31} \mathrm{P}\left\{{ }^{1} \mathrm{H}\right\}$ NMR changes drastically from two doublets for $\mathbf{1}$ (vide supra) to a broad singlet at $24.76 \mathrm{ppm}$ for $\mathbf{5}$ and the ${ }^{1} \mathrm{H}$ NMR displays a doublet for four hydrogen atoms at $2.99 \mathrm{ppm}$, demonstrating solution-state equivalence of the methylene side arms. NMR data suggests that the addition across the side arm is irreversible in the case of this weakly basic amine.

Single crystals of $\mathbf{5}$ suitable for X-ray diffraction were grown by slow diffusion of pentane into a toluene solution (Figure 2). The molecular structure confirms activation of $\mathrm{H}_{2} \mathrm{NAr}$ across both the metal center and ligand. In the solid state, one of the phosphorus arms of the $\mathrm{PNP}^{\mathrm{tBu}}$ pincer ligand is detached from the metal center, render-

ing complex $\mathbf{5}$ tetrahedral. A tetrahedral geometry is quite common for four-coordinate zinc centers ${ }^{46}$ and the conformation also resembles the structure found for $\mathrm{PNP}^{\mathrm{tBu}} \mathrm{ZnCl}_{2}$ (see Supporting Information); however, the NMR spectroscopy data indicates an equivalence of the side arms in solution consistent with a 5coordinate zinc center, hinting that there may be a difference between the solid and solution state behavior for both 3 and $\mathbf{5}$. To probe this difference, a variable temperature NMR experiment was performed for 5. At low temperature, inequivalence of the methylene and tert-butyl groups on the side arms by ${ }^{1} \mathrm{H}$ NMR (Figure 3) and the phosphorus linkers by ${ }^{31} \mathrm{P}\left\{{ }^{1} \mathrm{H}\right\}$ NMR (see Supporting Information) could be observed. Decoalescence of the signals is observed around $253 \mathrm{~K}$ and $238 \mathrm{~K}$ in the ${ }^{1} \mathrm{H}$ NMR and ${ }^{31} \mathrm{P}\left\{{ }^{1} \mathrm{H}\right\}$ NMR spectra, respectively. We also performed the analogous experiment with compound 3 and observe the same phenomenon (see Supporting Information). These experiments confirm the labile nature of the phosphorus linkers in solution and are significant in that the hemilability of the side arm of PNP ${ }^{\mathrm{tBu}}$ complexes has been proposed, but, to our knowledge, has never been demonstrated experimentally. This finding is meaningful in that hemilability in pincer complexes has been extensively studied ${ }^{47-51}$ and is believed to be significant in catalytic mechanisms of related compounds. ${ }^{52}$

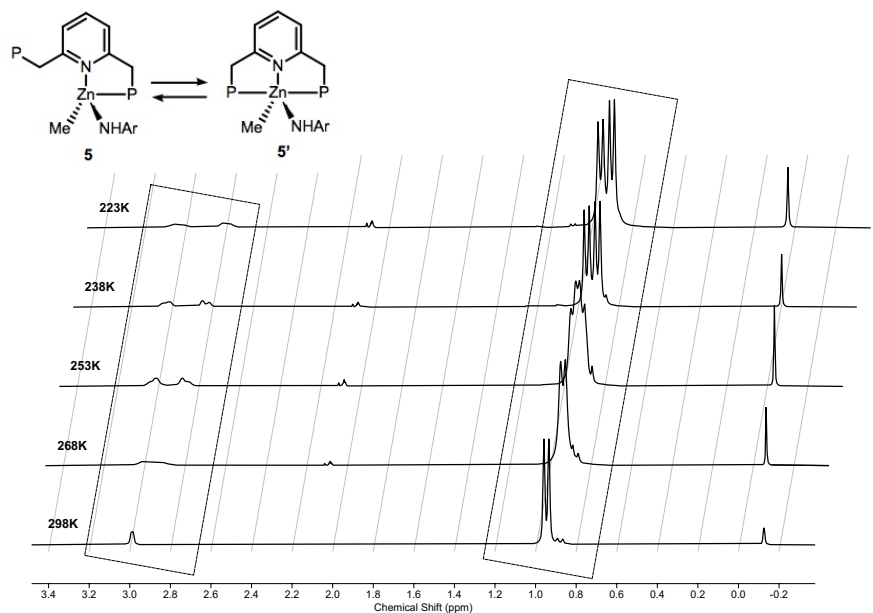

Figure 3. Select region of the ${ }^{1} \mathrm{H}$ NMR spectrum of $\mathbf{5}$ at variable temperatures. Dashed regions indicate the observable inequivalence of the methylene hydrogen atoms (left) and the tert-butyl hydrogen atoms (right) as temperature decreases (from bottom to top). Peak at 2.08 is toluene; peak below 0 is $\mathrm{Zn}(\underline{\mathrm{Me}})$.

Most interestingly, addition of the more basic N-benzylaniline $(\mathrm{PhN}(\mathrm{H}) \mathrm{Bn})$ to $\mathbf{1}$ under ambient conditions resulted in an observable equilibrium. Analysis of a mixture of $\mathrm{PNP}^{\mathrm{t} \mathrm{Bu} *} \mathrm{ZnMe}(\mathbf{1})$ and $\mathrm{PhN}(\mathrm{H}) \mathrm{Bn}$ by ${ }^{1} \mathrm{H}$ and ${ }^{31} \mathrm{P}\left\{{ }^{1} \mathrm{H}\right\}$ NMR spectroscopies indicates the formation of an equilibrium mixture containing three major species: free amine, dearomatized zinc methyl complex with coordinated amine $(6),{ }^{53}$ and the $\mathrm{N}-\mathrm{H}$ activated compound, $\mathrm{PNP}^{\mathrm{t}-}$ ${ }^{\mathrm{Bu}} \mathrm{Zn}(\mathrm{Me}) \mathrm{NPhBn}(7)$ (Scheme 2). Compound 7 is characterized as a component of the equilibrium mixture by NMR spectroscopy. Specifically, diagnostic signals at $23.19 \mathrm{ppm}$ in the ${ }^{31} \mathrm{P}\left\{{ }^{1} \mathrm{H}\right\}$ NMR spectrum for the solution-state equivalent phosphorus atoms and at $4.33 \mathrm{ppm}$ in the ${ }^{1} \mathrm{H}$ NMR spectrum for the $-\mathrm{CH}_{2} \mathrm{Ph}$ moiety in the amido ligand are observed. In addition, a small amount $(<5 \%)$ of a species tentatively identified as $\mathrm{PNP}^{\mathrm{tBu}} \mathrm{ZnNPhBn}$ is formed. This species exhibits ${ }^{31} \mathrm{P}\left\{{ }^{1} \mathrm{H}\right\}$ NMR characteristic signals similar to $\mathbf{1}$ and 
is presumably formed from protolytic cleavage of the $\mathrm{Zn}-\mathrm{Me}$ bond. The equilibrium between complexes 1, 6 and free amine and complex 7 could be probed by NMR spectroscopy via a variable temperature NMR study. Specifically, a $d_{8}$-toluene solution of a roughly equimolar mixture of $\mathrm{PNP}^{\mathrm{BBu} *} \mathrm{ZnMe}$ and $\mathrm{N}$-benzylaniline was heated in increments from room temperature to $120^{\circ} \mathrm{C}$, allowing the overall equilibrium between $\mathbf{1}$ and $\mathbf{7}$ to be established at each temperature. $\mathrm{K}_{\mathrm{eq}}$ was determined by integration of the corresponding ${ }^{1} \mathrm{H}$ NMR spectra and a Van 't Hoff plot permitted extraction of thermodynamic quantities (see Supporting Information). $K_{\text {eq }}$ over the temperature range was found to be between 1 and 100, with an experimentally determined $\mathrm{K}_{\mathrm{eq}}$ of 68.8 for the equilibrium mixture at $298 \mathrm{~K}$, associated with a $\Delta \mathrm{G}$ of $-2.4 \mathrm{kcal} / \mathrm{mol}$, which agrees reasonably well with our computed results $(+1.1 \mathrm{kcal} / \mathrm{mol}$ at $393.15 \mathrm{~K}$ and $1 \mathrm{M}$ standard states, vide infra). Observation of this equilibrium provides evidence that $(i)$ free amine can coordinate to and then react with 1 via MLC to rearomatize the ligand and generate 7, (ii) free amine can be released by MLC to regenerate $\mathbf{1}$ and (iii) that the reactants and product are quite similar energetically, such that the equilibrium is observable in solution by NMR spectroscopy. This unprecedented reversible $\mathrm{N}-\mathrm{H}$ bond activation by MLC with a main group metal resembles transition-metal-like behavior.

Scheme 2. Reactivity of 1 Towards $P h N(H) B n, H_{2}$ and $D_{2}$ and Trapping of a Proposed Zinc Hydride Complex
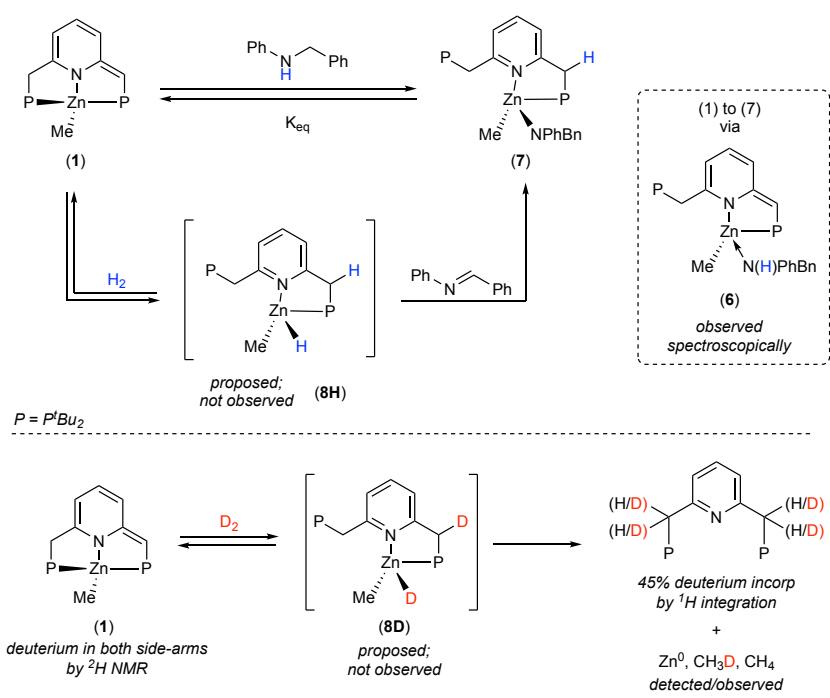

Subsequently, we turned our attention to the activation of a nonpolar, environmentally relevant substrate, $\mathrm{H}_{2}$. Oxidative addition of $\mathrm{H}_{2}$ to a transition metal is very important in several transition-metal catalyzed processes, ${ }^{54}$ and we have observed reversible $\mathrm{H}_{2}$ activation by MLC with related transition metal systems with applications in (de)hydrogenation catalysis. ${ }^{24,55}$ Thus, we explored whether $\mathrm{PNP}^{\mathrm{tBu} *} \mathrm{ZnMe}$ could potentially activate hydrogen, a challenging non-polar bond, in the same fashion as the N-H bond. Treatment of a solution of $\mathbf{1}$ in toluene with 5 bar of $\mathrm{H}_{2}$ in a high-pressure J. Young tube resulted in no significant change, even upon gradual heating to $80^{\circ} \mathrm{C}$. Heating the sample at $90^{\circ} \mathrm{C}$, however, resulted in partial decomposition, with grey precipitation presumed to be $\mathrm{Zn}^{0}$ and the reformation of the pro-ligand, $\mathrm{PNP}^{\mathrm{tBu}}$. The reaction could be driven to completion by heating at $120^{\circ} \mathrm{C}$ for two days. We hypothesized that if $\mathrm{H}_{2}$ activation was indeed occurring via MLC, a zinc hydride species, $\mathrm{PNP}^{\mathrm{tBu}} \mathrm{Zn}(\mathrm{Me}) \mathrm{H}(\mathbf{8 H}$, Scheme 2), may be an intermediate in this decomposition pathway. Note that numerous zinc hydride complexes have been described in the literature.,18 Additionally, computation indicates that $\mathbf{8 H}$ is only $2.5 \mathrm{kcal} / \mathrm{mol}$ higher in energy than $\mathbf{1}$ and free hydrogen, but that a barrier of 33.3 $\mathrm{kcal} / \mathrm{mol}$ exists to split the $\mathrm{H}_{2}$ molecule by MLC (vide infra). This suggests that while $\mathbf{8 H}$ may be accessible, it might be unstable under the conditions required for its generation. As such, we performed the hydrogen addition again at $120^{\circ} \mathrm{C}$ in a toluene solution, but now in the presence of a free imine, N-benzylideneaniline, in order to possibly trap the in situ formed hydride. Gratifyingly, we observed no decomposition, and instead, formation of the aforementioned equilibrium mixture of complexes $\mathbf{1}, \mathbf{6}$ and free amine and complex 7 (Scheme 2) by ${ }^{1} \mathrm{H}$ and ${ }^{31} \mathrm{P}\left\{{ }^{1} \mathrm{H}\right\}$ NMR spectroscopy. This result likely implicates insertion of the imine into a $\mathrm{Zn}-\mathrm{H}$ bond and also hinted at possible catalytic hydrogenation applications.

To further our understanding of the proposed $\mathrm{H}_{2}$ activation via MLC, a solution of complex 1 in toluene was treated with 5 bars of $\mathrm{D}_{2}$. After heating at $90^{\circ} \mathrm{C}$ for 36 hours, in addition to the observation of some decomposition, ${ }^{2} \mathrm{H}$ NMR spectroscopy confirmed that deuterium was incorporated into both side arms of 1 (14\% incorporation). After further heating at $120^{\circ} \mathrm{C}$ for one week, similar to our observations with $\mathrm{H}_{2}$, complete decomposition of $\mathbf{1}$ occurred to a major species (>95\%) with spectroscopic properties similar to the reprotonated $\mathrm{PNP}^{\mathrm{tBu}}$ ligand; the ${ }^{2} \mathrm{H} \mathrm{NMR}$ spectrum and integration of the methylene protons in the ${ }^{1} \mathrm{H}$ NMR spectrum confirmed incorporation of deuterium ( $45 \%$ incorporation) into the free ligand arms (Scheme 2). In addition, a grey solid, again presumed to be $\mathrm{Zn}^{0}$, was observed lining the walls of the NMR tube, and both $\mathrm{CH}_{3} \mathrm{D}$ and $\mathrm{CH}_{4}$ were detected by ${ }^{1} \mathrm{H}$ NMR spectroscopy (see Supporting Information). ${ }^{56}$ This result further suggests the activation of $\mathrm{H}_{2}$ (and $\mathrm{D}_{2}$ ) via MLC. Moreover, observable incorporation of deuterium into 1 and the $45 \%$ deuterium incorporation into the free ligand at the end of the reaction both imply that the $\mathrm{H}_{2} / \mathrm{D}_{2}$ activation is reversible. While dihydrogen has been utilized as the hydride source in the preparation of zinc hydride derivatives, ${ }^{13,57}$ we are unaware of any examples of reversible hydrogen activation by molecular zinc species. Nonetheless, it is noteworthy that the relatively low incorporation likely indicates that the decomposition pathway in the absence of imine is facile as compared to the reverse dehydrogenation process. Finally, to confirm the role of the zinc center in the $\mathrm{H}_{2} / \mathrm{D}_{2}$ activation, a control experiment was performed with the $\mathrm{PNP}^{\mathrm{tBu}}$ free ligand and $\mathrm{D}_{2}$. No incorporation of deuterium into the side arms was observed when employing the same conditions (see Supporting Information).

Based on the unique activity of the main group metal zinc-based pincer complex towards $\mathrm{H}_{2}$ cleavage, insertion and reversible activation of N-H bonds (vide supra), we posited that leveraging MLC might permit hydrogenation of polar unsaturated bonds with this system. To our knowledge, zinc catalyzed hydrogenation has been demonstrated for imines under very high $\mathrm{H}_{2}$ pressures (68-100 bar) $)^{13,14}$ and ketones with limited scope and high $\mathrm{H}_{2}$ pressure $(100$ bar) ${ }^{58}$ Reductions catalyzed by molecular zinc compounds utilizing other hydrogen sources, specifically hydrosilanes and hydroboranes, have been demonstrated, including imines, ketones, aldehydes and nitriles. ${ }^{2,10,11,59}$ The lack of reports of hydrogenation, we believe, is related to the energetic cost of sigma bond metathesis to split hydrogen and release product (hence the success of other hydrogen sources with more favorable thermodynamic driving forces). Given the ability of the aromatization/dearomatization MLC approach to facilitate the reversible activation of $\mathrm{H}_{2}$ and N-H 
bonds in this pincer system, we hypothesized that these alternate pathways could potentially bypass other more energetically demanding routes with less favorable thermodynamics, thus allowing hydrogenation at milder conditions compared to previously reported studies.

Indeed, $\mathrm{PNP}^{\mathrm{EB} u} \mathrm{ZnMe}(\mathbf{1})$ is a moderately active catalyst for the hydrogenation of a model substrate, N-benzylideneaniline (Table 1 , Entry 1 ), at substantially lower pressures ( 7 bars) than the previous reports (68-80 bars) of zinc-catalyzed imine hydrogenation..$^{13,14}$ Specifically, when $0.5 \mathrm{mmol}$ of N-benzylideneaniline in $1.8 \mathrm{~mL}$ toluene was treated with 7 bars of $\mathrm{H}_{2}$ in the presence of $\mathbf{1}$ (2.5 mol\%) at $120^{\circ} \mathrm{C}$, the corresponding amine was observed by GCMS and ${ }^{1} \mathrm{H}$ NMR spectroscopy in up to $89 \%$ yield after 18 hours. Various substituted benzylideneaniline derivatives, with both electron donating and electron withdrawing groups on the phenyl ring, were also hydrogenated to their corresponding amines under similar conditions with high to excellent yields (Entries 2-6). Upon changing the R" group on nitrogen from phenyl to alkyl moieties, higher pressure is needed to obtain substantial conversion (Entries 7-10). Interestingly, N-benzylidene-t-butylamine was not amenable to hydrogenation under the reaction conditions, most probably due to the bulky "Bu group (Entry 8). On the other hand, as the R" group was changed to a less bulky alkyl group ( $\mathrm{Me}, \mathrm{Bn})$, hydrogenation to the corresponding amine products was observed (Entries 7 and 9). R' on carbon is not limited to aromatic substituents; while aldimines with aliphatic $\mathrm{R}^{\prime}$ are relatively elusive, we also found that N-butylbenzylamine can be prepared from the corresponding imine, N-butylidenebenzylamine, in moderate yield with a somewhat longer reaction time (Entry 10). Finally with respect to imines, we demonstrate that $\mathbf{1}$ also catalyzes hydrogenation of a ketimine, specifically phenyl-(1-phenylethylidene)amine, in good yield (Entry 11).

While several main group metals exhibit activity for imine hydrogenation, homogeneous ketone hydrogenation by main group metals is exceptionally limited. Select examples exist requiring extremely high pressures, ${ }^{58,60,61}$ the use of additives ${ }^{62}$ or that exhibit narrow substrate scope ${ }^{58,60,63}$ Thus, it is significant that we found that $\mathbf{1}$ can catalyze the hydrogenation of ketones with aromatic, aliphatic and mixed aromatic/aliphatic $\mathrm{R}$ and R' substituents under 65 bar of $\mathrm{H}_{2}$ at $140^{\circ} \mathrm{C}$. Specifically, benzophenone is hydrogenated to diphenylmethanol in up to $88 \%$ yield (Entry 12). Additionally, compound $\mathbf{1}$ catalyzes hydrogenation of 4-heptanone to 4-heptanol and propiophenone to 1-phenyl-1-propanol in good yield (Entries 1314). With respect to green chemistry, utilizing zinc is inherently significant for these transformations, but also, it is important that (i) there is no need for any base or other additives and (ii) the process is $100 \%$ atom economical (as opposed to previously reported zinc reductions with hydrosilanes and hydroboranes)..$^{59,64}$

Mechanistically, we propose a plausible cycle (Figure 4) accounting for the observations from the stoichiometric and catalytic experiments. In the first step, the arm of $\mathrm{PNP}^{\mathrm{BB} u *} \mathrm{ZnMe}(\mathbf{A})$, can open (B) allowing for the reversible activation of hydrogen by MLC to generate an aromatized zinc hydride intermediate $(\mathbf{C})$. In the presence of imine or ketone, rather than decomposing, the zinc hydride can be trapped via an insertion pathway, generating the aromatized zinc amido or alkoxy complex (E) (vide supra, Scheme 2). Several pathways seem plausible for the insertion to proceed, but here we propose one concerted path (direct to $\mathbf{E}$ ) and one stepwise path (via $\mathbf{D}$, see Supporting Information). Insertion of imines or ketones into a zinc hydride bond has been previously proposed and observed. ${ }^{11,64,65}$ The aromatized zinc amido or alkoxy complex, per the stoichiometric experiments, can release product across the side arm

Table 1. Hydrogenation of Imines and Ketones Catalyzed by $\mathbf{1}$

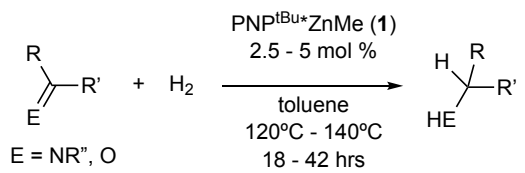

\begin{tabular}{|c|c|c|c|c|c|c|}
\hline Entry" & & $\begin{array}{l}\text { Loading } \\
\text { mol\% }\end{array}$ & $\begin{array}{l}\text { Pressure } \\
\text { bar }\end{array}$ & $\begin{array}{c}\text { Temp } \\
{ }^{\circ} \mathrm{C}\end{array}$ & $\begin{array}{l}\text { Time } \\
\text { hrs }\end{array}$ & Yield \\
\hline 1 & & 2.5 & 7 & 120 & 18 & $79-89 \%^{f}$ \\
\hline 2 & & 2.5 & 7 & 120 & 18 & $76 \%$ \\
\hline $3^{\mathrm{d}}$ & & 2.5 & 7 & 120 & 18 & $>95 \%$ \\
\hline 4 & & 2.5 & 7 & 120 & 18 & $81 \%$ \\
\hline 5 & & 2.5 & 7 & 120 & 18 & $93 \%$ \\
\hline 6 & & 5 & 7 & 120 & 18 & $>95 \%$ \\
\hline 7 & & 5 & 30 & 120 & 18 & $>95 \%$ \\
\hline 8 & & 5 & 30 & 120 & 18 & $0 \%$ \\
\hline 9 & & 5 & 30 & 120 & 18 & $74 \%$ \\
\hline 10 & & 5 & 30 & 120 & 42 & $67 \%$ \\
\hline $11^{\mathrm{e}}$ & & 5 & 30 & 120 & 42 & $79 \%$ \\
\hline 12 & & 5 & 65 & 140 & 42 & $73-88 \%^{\mathrm{f}}$ \\
\hline 13 & & 5 & 65 & 140 & 42 & $70 \%$ \\
\hline $14^{e}$ & & 5 & 65 & 140 & 42 & $80 \%$ \\
\hline
\end{tabular}

a) Standard Conditions: $0.5 \mathrm{mmol}$ substrate, $1.8 \mathrm{~mL}$ toluene; \% catalyst, $\mathrm{H}_{2}$ pressure, temperature and time as specified b) Product confirmed by GC-MS c) Yield determined by ${ }^{1} \mathrm{H}$ NMR spectroscopy of the crude reaction mixture with respect to mesitylene as an internal standard d) $3.6 \mathrm{~mL}$ of solvent used to improve substrate solubility e) no enantioselectivity observed f) Range for 3 independent trials 

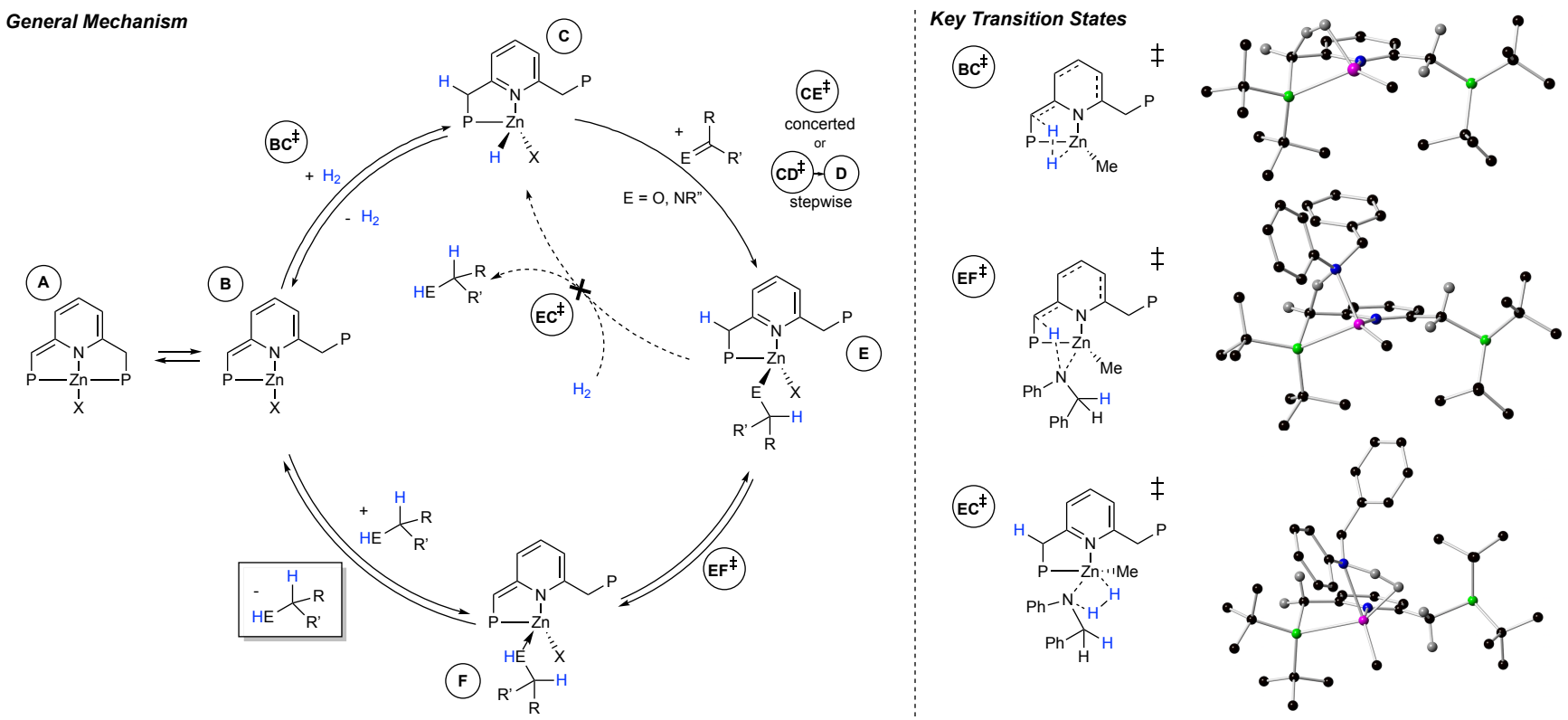

Free Energy Profile
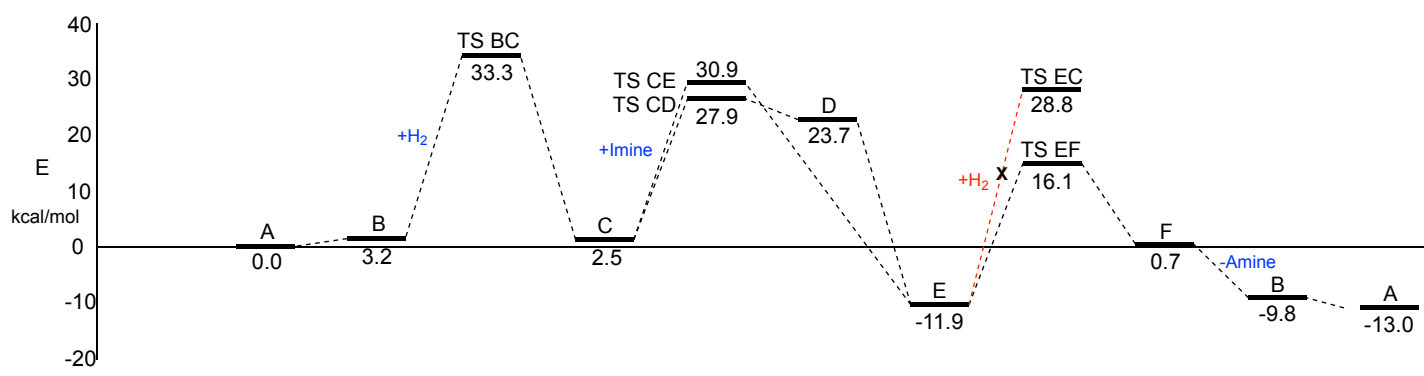

Figure 4. Proposed Catalytic Cycle and DFT Summary for imine and ketone hydrogenation in which $\mathrm{P}=\mathrm{P}^{\mathrm{t}} \mathrm{Bu} \mathrm{u}_{2}, \mathrm{X}=\mathrm{Me}$ or $\mathrm{EC}(\mathrm{H})(\mathrm{R})\left(\mathrm{R}^{\prime}\right)$ and where $\mathrm{E}=\mathrm{O}$ or NR". Computed transition states and Gibbs free energy profile shown for $\mathrm{X}=\mathrm{Me}$; $E \mathrm{C}=(\mathrm{R}) \mathrm{R}^{\prime}=$ $\mathrm{PhN}=\mathrm{C}(\mathrm{H}) \mathrm{Ph}$. Only key hydrogen atoms and only central carbon shown for ${ }^{\mathrm{B}} \mathrm{Bu}$ groups in computed structures for clarity. Gibbs free energies are in $\mathrm{kcal} / \mathrm{mol}$ with respect to the starting materials $\left(\mathbf{1}, \mathrm{H}_{2}\right.$ and $\left.\mathrm{PhN}=\mathrm{C}(\mathrm{H}) \mathrm{Ph}\right)$ at $393.15 \mathrm{~K}$. See Supporting Information for complete $\begin{array}{lllllll}\text { computational } & \text { details } & \text { and } & \text { TSCE, } & \text { TSCD } & \text { and } & \text { D. }\end{array}$

via MLC (through intermediate $\mathbf{F}$ ), regenerating the dearomatized zinc methyl complex (A and $\mathbf{B}$ ) to propagate the cycle. It is worth noting that the zinc amido or alkoxy intermediate (E) could also undergo sigma bond metathesis with hydrogen(a more typical mechanism for a main group metal) via a more energetically demanding pathway (vide infra), which would also be a productive route to regenerate $(\mathbf{C}){ }^{13}$

DFT calculations at the $\omega \mathrm{B} 97 \mathrm{M}-\mathrm{V} / \mathrm{def2}$-TZVPP /RIJCOSX/SMD//M06-L/def2-TZVP/GD3/W06 level of theory were performed on the model system $(\mathrm{X}=\mathrm{Me}$; substrate = $\mathrm{N}$-benzylideneaniline, $1 \mathrm{M}$ standard states except $\mathrm{H}_{2} 7 \mathrm{~atm}$ ) to provide insight into the plausibility of the proposed mechanism and to interrogate specifically whether product release via MLC (loss of amine from $\mathbf{E}$ to $\mathbf{F}$ to $\mathbf{B}$ ) versus product release by hydrogenolysis (hydrogenation of $\mathbf{E}$ to $\mathbf{C}$ ) is more favorable. In particular, computation indicates that the largest activation energy of the MLC pathway is the initial activation of hydrogen, which is overall $7.4 \mathrm{kcal} / \mathrm{mol}$ lower in energy than the highest energy barrier of the sigma bond metathesis pathway, which is the activation of hydrogen at the zinc amido complex ( $\mathbf{E}$ to $\mathbf{C}$; activation energy: $40.7 \mathrm{kcal} / \mathrm{mol}$ ). Loss of amine via MLC has a barrier of 28.0 $\mathrm{kcal} / \mathrm{mol}$ (E to $\mathbf{F}$ ), which is $12.7 \mathrm{kcal} / \mathrm{mol}$ lower in energy than the hydrogenolysis product-forming step of the alternative mech- anism. This difference supports the notion that both hydrogen activation and loss of amine through the MLC pathway is substantially more favorable than splitting hydrogen by sigma bond metathesis to generate product (see Supporting Information for full computational details).

To further probe these possible mechanisms, we also performed the hydrogenation experiments with zinc alkyl and amido species without the PNP ${ }^{\mathrm{tBu}}$ ligand, which would be unable to proceed by a MLC pathway. Dimethylzinc alone shows no activity for imine hydrogenation under the standard conditions. Zinc bis(trimethylsilyl)amide, however, showed some activity across several experimental trials $;{ }^{16}$ however, a mercury test suppressed much of its activity for imine hydrogenation, and several trials of the same conditions led to variant results, leading us to believe that this activity is heterogeneous. Supporting this hypothesis, under the ketone hydrogenation conditions, zinc bis(trimethylsilyl)amide alone again gave varying results, and additionally suffers from selectivity problems (see Supporting Information). On the contrary, the presence of mercury had limited to no effect on the activity of $\mathbf{1}$ for both imine and ketone hydrogenation. Nonetheless, considering these computational and experimental findings, a contribution of the sigma bond metathesis pathway is unlikely but possible, and in addition, we can- 
not rule out other possible outer sphere mechanisms or an FLPlike mechanism involving the labile arm, which was recently reported for a copper pincer complex. ${ }^{66}$ In that respect, it is interesting to note that the proposed pathway does not specifically implicate the labile arm, indicating that PN complexes may also be suitable for such transformations. ${ }^{43,67}$

Finally, with respect to the resting state and active catalytic species, we also note that during the course of the catalytic reaction, the zinc methyl moiety (denoted X in Figure 4) may be protonated with product (supported by the observation of the proposed complex, $\mathrm{PNP}^{\mathrm{tB} \mathrm{B} *} \mathrm{ZnNPhBn}$, in the equilibrium described above), especially as the concentration of amine or alcohol increases during the reaction. This substitution may or may not enhance the catalytic activity of the system. Indeed, monitoring the hydrogenation of 5 equivalents of $\mathrm{N}$-benzylideneaniline in an NMR tube with 5 bar of hydrogen, in addition to free amine product, during the reaction we observed $\mathbf{1}$ with bound amine (6) and 7 in equilibrium as the major species, but also a species that may be the activation of the free imine across the side arm which forms initially (maximum observed concentration ca 30\%) and then decays as hydrogenation proceeds (depicted as $\mathbf{G}$, but may be one of several isomers; See Supporting Information ${ }^{68}$ and observable amounts of $\mathrm{PNP}^{\mathrm{BB} *} \mathrm{ZnNPhBn}$. Therefore, this finding, in conjunction with the aforementioned equilibrium experiment and $\mathrm{Zn}-\mathrm{H}$ trapping experiment (outlined in Scheme 2) suggest that the formation of $\mathrm{PNP}^{\mathrm{tBu} *} \mathrm{ZnNPhBn}$ depends on the ratio of free amine to zinc complex in the system. We hypothesized that $\mathrm{PNP}^{\mathrm{BBu}} \mathrm{ZnNPhBn}$ is likely also catalytically competent. In accordance, complex $\mathbf{4}$, prepared in situ from 3 and $\mathrm{NaN}\left(\mathrm{SiMe}_{3}\right)_{2}$, is also active for imine and ketone hydrogenation. Regardless of the $\mathrm{X}$ substitution, in agreement with the computation, activation of hydrogen via MLC is likely the rate-determining step of the catalytic cycle. Further supporting this notion, we observe an approximate kinetic isotope effect of 1.71 when the model imine hydrogenation is performed in a high-pressure NMR tube with a mixture of $\mathrm{H}_{2}$ and $\mathrm{D}_{2}$ (See Supporting Information).

\section{CONCLUSION}

In conclusion, a series of dearomatized zinc pincer complexes supported by the $\mathrm{PNP}^{\mathrm{EB}}$ ligand were prepared and characterized.

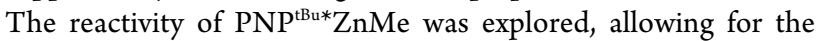
unique observation of reversible $\mathrm{N}-\mathrm{H}$ and $\mathrm{H}-\mathrm{H}$ bond activation by MLC by a main group metal complex. Mechanistic studies indicate that hemilability of the phosphorus arms is key in allowing for this novel bond activation by zinc. Utilizing this zinc pincer system in catalysis, imines and ketones have been hydrogenated via a mechanism in which aromatization/dearomatization MLC was found to play a role in key steps of the catalytic cycle: $\mathrm{H}_{2}$ activation and product release. Thus, leveraging MLC shows significant promise in advancing main group metal (de)hydrogenation catalysis. The study of further bond activations and catalytic applications of this system is currently underway, with the aim of broadening the capabilities of main group catalysts.

\section{ASSOCIATED CONTENT}

\section{Supporting Information}

The Supporting Information is available free of charge on the ACS Publications website.
General Information, Experimental Details, Computational Details (PDF)

X-Ray Data for Compounds 1-5 (ZIP/CIFs)

\section{AUTHOR INFORMATION}

\section{Corresponding Author}

*david.milstein@weizmann.ac.il

\section{Present Addresses}

+ Current address: School of Chemistry, University of St. Andrews, North Haugh, St. Andrews, KY169ST, Scotland, UK.

\section{Notes}

The authors declare no competing financial interests.

\section{ACKNOWLEDGMENT}

We thank the European Research Council (ERC AdG 692775) for support of this research. M.R. acknowledges the Zuckerman STEM Leadership Program for a research fellowship. S.K. acknowledges the Sustainability and Energy Research Initiative (SAERI) Weizmann Institute of Science for a research fellowship. A. K. is thankful to the Feinberg Graduate School for the Senior Postdoctoral Fellowship. We thank Niklas von Wolff and Mark Iron for computation assistance and Trevor Janes and Moran Feller for helpful discussion. We thank Dr. Arye Tishbee for MS analysis. D.M. is the Israel Matz Professorial Chair of Organic Chemistry.

\section{REFERENCES}

(1) Gunanathan, C.; Milstein, D. "Metal-Ligand Cooperation by Aromatization-Dearomatization: A New Paradigm in Bond Activation and "Green" Catalysis" Acc. Chem. Res. 2011, 44, 588-602.

(2) Enthaler, S. "Rise of the Zinc Age in Homogeneous Catalysis?" ACS Catal. 2013, 3, 150-158.

(3) Power, P. P. "Main-group elements as transition metals" Nature 2010, $463,171-177$.

(4) Hill, M. S.; Liptrot, D. J.; Weetman, C. "Alkaline earths as main group reagents in molecular catalysis" Chem. Soc. Rev. 2016, 45, 972-988.

(5) Gunanathan, C.; Milstein, D. "Applications of Acceptorless Dehydrogenation and Related Transformations in Chemical Synthesis" Science 2013, 341, 249-262.

(6) Chu, T.; Nikonov, G. I. "Oxidative Addition and Reductive Elimination at Main-Group Element Centers" Chem. Rev. 2018, 118, 3608-3680.

(7) Zhang, X.; Emge, T. J.; Hultzsch, K. C. "A Chiral Phenoxyamine Magnesium Catalyst for the Enantioselective Hydroamination/Cyclization of Aminoalkenes and Intermolecular Hydroamination of Vinyl Arenes" Angew. Chem. Int. Ed. 2012, 51, 394-398.

(8) Cheng, M.; Attygalle, A. B.; Lobkovsky, E. B.; Coates, G. W. "Single-Site Catalysts for Ring-Opening Polymerization: Synthesis of Heterotactic Poly(lactic acid) from rac-Lactide" J. Am. Chem. Soc. 1999, 121, 11583-11584.

(9) Rauch, M.; Parkin, G. "Zinc and Magnesium Catalysts for the Hydrosilylation of Carbon Dioxide" J. Am. Chem. Soc. 2017, 139, 18162-18165.

(10) Rit, A.; Zanardi, A.; Spaniol, T. P.; Maron, L.; Okuda, J. "A Cationic Zinc Hydride Cluster Stabilized by an N-Heterocyclic Carbene: Synthesis, Reactivity, and Hydrosilylation Catalysis" Angew. Chem. Int. Ed. 2014, 53, 13273-13277.

(11) Sattler, W.; Ruccolo, S.; Rostami Chaijan, M.; Nasr Allah, T.; Par- 
kin, G. "Hydrosilylation of Aldehydes and Ketones Catalyzed by a Terminal Zinc Hydride Complex, [ $\left.\kappa^{3}-\mathrm{Tptm}\right] \mathrm{ZnH"}$ Organometallics 2015, 34, 4717-4731.

(12) Rauch, M.; Ruccolo, S.; Parkin, G. "Synthesis, Structure, and Reactivity of a Terminal Magnesium Hydride Compound with a Carbatrane Motif, [Tism $\left.{ }^{\text {PriBenz }}\right] \mathrm{MgH}$ : A Multifunctional Catalyst for Hydrosilylation and Hydroboration" J. Am. Chem. Soc. 2017, 139, 13264-13267.

(13) Jochmann, P.; Stephan, D. W. " $\mathrm{H}_{2}$ Cleavage, Hydride Formation, and Catalytic Hydrogenation of Imines with Zinc Complexes of $\mathrm{C}_{5} \mathrm{Me}_{5}$ and N-Heterocyclic Carbenes" Angew. Chem. Int. Ed. 2013, 52, 9831-9835.

(14) Werkmeister, S.; Fleischer, S.; Junge, K.; Beller, M. "Towards a Zinc-Catalyzed Asymmetric Hydrogenation/Transfer Hydrogenation of Imines" Chem. Asian. J. 2012, 7, 2562-2568.

(15) Spielmann, J.; Buch, F.; Harder, S. "Early Main-Group Metal Catalysts for the Hydrogenation of Alkenes with $\mathrm{H}_{2}$ "Angew. Chem. Int. Ed. 2008, 47, 9434-9438.

(16) Bauer, H.; Alonso, M.; Färber, C.; Elsen, H.; Pahl, J.; Causero, A.; Ballmann, G.; De Proft, F.; Harder, S. "Imine hydrogenation with simple alkaline earth metal catalysts" Nature Catal. 2018, 1, 40-47.

(17) Elliott, D. C.; Marti, A.; Mauleón, P.; Pfaltz, A. " $\mathrm{H}_{2}$ Activation by Non-Transition-Metal Systems: Hydrogenation of Aldimines and Ketimines with $\mathrm{LiN}\left(\mathrm{SiMe}_{3}\right)_{2}$ "Chem. Eur. J. 2019, 25, 1918-1922.

(18) Wiegand, A.-K.; Rit, A.; Okuda, J. "Molecular zinc hydrides" Coord. Chem. Rev. 2016, 314, 71-82.

(19) Mukherjee, D.; Okuda, J. "Molecular Magnesium Hydrides" Angew. Chem. Int. Ed. 2018, 57, 1458-1473.

(20) Mukherjee, D.; Schuhknecht, D.; Okuda, J. "Hydrido Complexes of Calcium: A New Family of Molecular Alkaline-Earth-Metal Compounds" Angew. Chem. Int. Ed. 2018, 57, 9590-9602.

(21) Li, Y., Junge, K. and Beller, M. (2015). Zinc-Catalyzed Reductions of Unsaturated Compounds. Zinc Catalysis (eds S. Enthaler and X.F. Wu).

(22) Wu, X.-F.; Neumann, H. "Zinc-Catalyzed Organic Synthesis: C-C, C-N, C-O Bond Formation Reactions" Adv. Synth. Catal. 2012, 354, 3141-3160.

(23) Khusnutdinova, J. R.; Milstein, D. "Metal-Ligand Cooperation" Angew. Chem. Int. Ed. 2015, 54, 12236-12273.

(24) Gunanathan, C.; Milstein, D. "Bond Activation and Catalysis by Ruthenium Pincer Complexes" Chem. Rev. 2014, 114, 1202412087.

(25) Mukherjee, A.; Milstein, D. "Homogeneous Catalysis by Cobalt and Manganese Pincer Complexes" ACS Catalysis 2018, 8, 1143511469.

(26) Alig, L.; Fritz, M.; Schneider, S. "First-Row Transition Metal (De)Hydrogenation Catalysis Based On Functional Pincer Ligands" Chem. Rev. 2019, 119, 2681-2751.

(27) Fritz, M.; Schneider, S. (2019). The Renaissance of Base Metal Catalysis Enabled by Functional Ligands. The Periodic Table II: Catalytic, Materials, Biological and Medical Applications (ed Mingos, D. M. P.)

(28) Greb, L.; Ebner, F.; Ginzburg, Y.; Sigmund, L.M. "Element-Ligand Cooperativity with p-Block elements" Eur. J. Inorg. Chem. 10.1002/ejic.202000449

(29) Simler, T.; Karmazin, L.; Bailly, C.; Braunstein, P.; Danopoulos, A. A. "Potassium and Lithium Complexes with Monodeprotonated, Dearomatized PNP and PNC ${ }^{\mathrm{NHC}}$ Pincer-Type Ligands" Organometallics 2016, 35, 903-912.

(30) Myers, T. W.; Berben, L. A. "Aluminum-Ligand Cooperative N-H Bond Activation and an Example of Dehydrogenative Coupling" J. Am. Chem. Soc. 2013, 135, 9988-9990.

(31) Myers, T. W.; Berben, L. A. "Aluminium-ligand cooperation promotes selective dehydrogenation of formic acid to $\mathrm{H}_{2}$ and $\mathrm{CO}_{2}{ }^{\prime \prime}$ Chem. Sci. 2014, 5, 2771-2777.

(32) Berben, L. A. "Catalysis by Aluminum(III) Complexes of NonInnocent Ligands" Chem. Eur. J. 2015, 21, 2734-2742.

(33) Abdalla, J. A. B.; Riddlestone, I. M.; Tirfoin, R.; Aldridge, S. "Cooperative Bond Activation and Catalytic Reduction of Carbon Diox- ide at a Group 13 Metal Center" Angew. Chem. Int. Ed. 2015, 54, 5098-5102.

(34) Pramanick, R.; Bhattacharjee, R.; Sengupta, D.; Datta, A.; Goswami, S. "An Azoaromatic Ligand as Four Electron Four Proton Reservoir: Catalytic Dehydrogenation of Alcohols by Its Zinc(II) Complex" Inorg. Chem. 2018, 57, 6816-6824.

(35) Chang, M.-C.; Dann, T.; Day, D. P.; Lutz, M.; Wildgoose, G. G.; Otten, E. "The Formazanate Ligand as an Electron Reservoir: Bis(Formazanate) Zinc Complexes Isolated in Three Redox States" Angew. Chem. Int. Ed. 2014, 53, 4118-4122.

(36) Cronin, S. P.; Strain, J. M.; Mashuta, M. S.; Spurgeon, J. M.; Buchanan, R. M.; Grapperhaus, C. A. "Exploiting Metal-Ligand Cooperativity to Sequester, Activate, and Reduce Atmospheric Carbon Dioxide with a Neutral Zinc Complex" Inorg. Chem. 2020, 59, 4835-4841.

(37) Ruccolo, S.; Rauch, M.; Parkin, G. "Synthesis and Structural Characterization of Tris(isopropylbenzimidazol-2-ylthio)methyl Zinc Complexes, $\left[\mathrm{Titm}^{\text {PriBenz}}\right] \mathrm{ZnX}$ : Modulation of Transannular $\mathrm{Zn}-\mathrm{C}$ Interactions" Organometallics 2018, 37, 1708-1718.

(38) D'Auria, I.; Lamberti, M.; Mazzeo, M.; Milione, S.; Roviello, G.; Pellecchia, C. "Coordination Chemistry and Reactivity of Zinc Complexes Supported by a Phosphido Pincer Ligand" Chem. Eur. J. 2012, 18, 2349-2360.

(39) Spielmann, J.; Piesik, D.; Wittkamp, B.; Jansen, G.; Harder, S. "Convenient synthesis and crystal structure of a monomeric zinc hydride complex with a three-coordinate metal center" Chem. Commun. 2009, 3455-3456.

(40) The Chemistry of Organozinc Compounds: R-Zn (eds. Rappoport, Z and Marek, I.) 2006

(41) Khaskin, E.; Iron, M. A.; Shimon, L. J. W.; Zhang, J.; Milstein, D. "N-H Activation of Amines and Ammonia by Ru via Metal-Ligand Cooperation" J. Am. Chem. Soc. 2010, 132, 8542-8543.

(42) For $\mathrm{Al}$ and $\mathrm{Ga}$, see references 30 and 33, respectively. For $\mathrm{Rh}$, see: Feller, M.; Diskin-Posner, Y.; Shimon, L. J. W.; Ben-Ari, E.; Milstein, D. "N-H Activation by $\mathrm{Rh}(\mathrm{I})$ via Metal-Ligand Cooperation" Organometallics 2012, 31, 4083-4101.

(43) de Boer, S. Y.; Gloaguen, Y.; Reek, J. N. H.; Lutz, M.; van der Vlugt, J. I. "N-H bond activation by palladium(II) and copper(I) complexes featuring a reactive bidentate PN-ligand" Dalton Trans. 2012, 41, 11276-11283.

(44) We cannot conclusively determine that this process is intramolecular, though it is quite likely given the experimental conditions and the computational findings regarding $\mathrm{N}-\mathrm{H}$ activation.

(45) Green, M. L. H.; Parkin, G. "Application of the Covalent Bond Classification Method for the Teaching of Inorganic Chemistry" J. Chem. Educ. 2014, 91, 807-816.

(46) Prince, R.H. (2006). Zinc: Inorganic \& Coordination Chemistry Encyclopedia of Inorganic Chemistry (eds R.B. King, R.H. Crabtree, C.M. Lukehart, D.A. Atwood and R.A. Scott).

(47) Poverenov, E.; Gandelman, M.; Shimon, L. J. W.; Rozenberg, H.; Ben-David, Y.; Milstein, D. "Pincer "Hemilabile" Effect. PCN Platinum(II) Complexes with Different Amine "Arm Length"" Organometallics 2005, 24, 1082-1090.

(48) Poverenov, E.; Gandelman, M.; Shimon, L. J. W.; Rozenberg, H.; Ben-David, Y.; Milstein, D. "Nucleophilic De-coordination and Electrophilic Regeneration of "Hemilabile" Pincer-Type Complexes: Formation of Anionic Dialkyl, Diaryl, and Dihydride $\mathrm{Pt}^{\mathrm{II}} \mathrm{Com}-$ plexes Bearing No Stabilizing $\pi$-Acceptors" Chem. Eur. J. 2004, 10 , 4673-4684.

(49) van der Vlugt, J. I.; Pidko, E. A.; Vogt, D.; Lutz, M.; Spek, A. L.; Meetsma, A. "T-Shaped Cationic $\mathrm{Cu}^{\mathrm{I}}$ Complexes with Hemilabile PNP-Type Ligands" Inorg. Chem. 2008, 47, 4442-4444.

(50) Adams, G. M.; Weller, A. S. "POP-type ligands: Variable coordination and hemilabile behaviour" Coord. Chem. Rev. 2018, 355, 150172.

(51) Cantat, T.; Scott, B. L.; Morris, D. E.; Kiplinger, J. L. "What a Difference a $5 f$ Element Makes: Trivalent and Tetravalent Uranium 
Halide Complexes Supported by One and Two Bis[2(diisopropylphosphino)-4-methylphenyl]amido (PNP) Ligands" Inorg. Chem. 2009, 48, 2114-2127.

(52) Braunstein, P.; Naud, F. "Hemilability of Hybrid Ligands and the Coordination Chemistry of Oxazoline-Based Systems" Angew. Chem. Int. Ed. 2001, 40, 680-699.

(53) Evidence for coordination of free amine to $\mathbf{1}$ is provided by a slight shift in the ${ }^{1} \mathrm{H}$ NMR of the signals of the parent complex. More evidently, upon coordination of free amine, there is a broadening of the ${ }^{31} \mathrm{P}\left\{{ }^{1} \mathrm{H}\right\}$ signals of $\mathbf{1}$, possibly due to disrupting the P-P coupling facilitated by the lability of the phosphorus arm (see Supporting Information).

(54) The Handbook of Homogeneous Hydrogenation (eds. de Vries J. G. \& Elsevier, C. J.) 2007.

(55) For irreversible $\mathrm{H}_{2}$ activation by gallium-ligand cooperation, see reference 33.

(56) The source of $\mathrm{Zn}^{0}$ and $\mathrm{CH}_{4}\left(\mathrm{CH}_{3} \mathrm{D}\right)$ is proposed to be $\mathrm{HZnMe}$ (DZnMe). See (a) Kahnes, M.; Görls, H.; González, L.; Westerhausen, M. "Synthesis and Catalytic Reactivity of Bis(alkylzinc)hydride-di(2-pyridylmethyl)amides" Organometallics 2010, 29, 3098-3108 (b) Flory, M. A.; Apponi, A. J.; Zack, L. N.; Ziurys, L. M. "Activation of Methane by Zinc: Gas-Phase Synthesis, Structure, and Bonding of HZnCH3" J. Am. Chem. Soc. 2010, 132, 1718617192.

(57) Jochmann, P.; Stephan, D. W. "The synthesis and structure of $\left[\mathrm{Zn}(\mathrm{TEMPO})_{2}\right]_{2}$ and $\left[\mathrm{Zn}(\mu-\mathrm{H})\left(\mu^{2}-\eta^{1}: \eta^{1}-\mathrm{TEMPO}\right)\right]_{6} "$ Chem. Commun. 2014, 50, 8395-8397.

(58) Jochmann, P.; Stephan, D. W. "Zincocene and Dizincocene NHeterocyclic Carbene Complexes and Catalytic Hydrogenation of Imines and Ketones" Chem. Eur. J. 2014, 20, 8370-8378.

(59) Szewczyk, M.; Bezłada, A.; Mlynarski, J. "Zinc-Catalyzed Enantioselective Hydrosilylation of Ketones and Imines under Solvent-Free Conditions" ChemCatChem 2016, 8, 3575-3579.

(60) (a) Walling, C.; Bollyky, L. "Homogeneous Hydrogenation in the Absence of Transition-Metal Catalysts" J. Am. Chem. Soc. 1964, 86, 3750-3752. (b) Walling, C.; Bollyky, L. "Base Catalyzed Homogeneous Hydrogenation" J. Am. Chem. Soc. 1961, 83, 2968-2969.
(61) Berkessel, A.; Schubert, T. J. S.; Müller, T. N. "Hydrogenation without a Transition-Metal Catalyst: On the Mechanism of the Base-Catalyzed Hydrogenation of Ketones" J. Am. Chem. Soc. 2002, 124, 8693-8698.

(62) Scott, D. J.; Phillips, N. A.; Sapsford, J. S.; Deacy, A. C.; Fuchter, M. J.; Ashley, A. E. "Versatile Catalytic Hydrogenation Using A Simple Tin(IV) Lewis Acid" Angew. Chem. Int. Ed. 2016, 55, 14738-14742.

(63) Other examples of non-transition metal catalyzed homogeneous ketone hydrogenation utilize FLPs. See, for example (a) Mahdi, T.; Stephan, D. W. "Enabling Catalytic Ketone Hydrogenation by Frustrated Lewis Pairs" J. Am. Chem. Soc. 2014, 136, 15809-15812. (b) Scott, D. J.; Fuchter, M. J.; Ashley, A. E. "Nonmetal Catalyzed Hydrogenation of Carbonyl Compounds" J. Am. Chem. Soc. 2014, 136, 15813-15816.

(64) Park, B.-M.; Mun, S.; Yun, J. "Zinc-Catalyzed Enantioselective Hydrosilylation of Imines" Adv. Synth. Catal. 2006, 348, 10291032.

(65) With respect to the insertion, other concerted, stepwise, innersphere and outersphere pathways are plausible. $\mathrm{Zn}(\mathrm{H}) \mathrm{Me}$ could also dissociate from the ligand prior to the insertion. This step is not rate determining, so only some possibilities were explored herein.

(66) Takeuchi, K.; Tanaka, Y.; Tanigawa, I.; Ozawa, F.; Choi, J.-C. " $\mathrm{Cu}(\mathrm{I})$ complex bearing a PNP-pincer-type phosphaalkene ligand with a bulky fused-ring Eind group: properties and applications to FLP-type bond activation and catalytic $\mathrm{CO}_{2}$ reduction" Dalton Trans. 2020, 49, 3630-3637.

(67) Devillard, M.; Alvarez Lamsfus, C.; Vreeken, V.; Maron, L.; van der Vlugt, J. I. "Versatile coordination of a reactive $\mathrm{P}, \mathrm{N}$-ligand toward boron, aluminum and gallium and interconversion reactivity" Dalton Trans. 2016, 45, 10989-10998.

(68) For related side-arm bond activation, see Montag, M.; Zhang, J.; Milstein, D. "Aldehyde Binding through Reversible C-C Coupling with the Pincer Ligand upon Alcohol Dehydrogenation by a PNPRuthenium Catalyst" J. Am. Chem. Soc. 2012, 134, 10325-10328.

\section{Table of Contents Graphic}

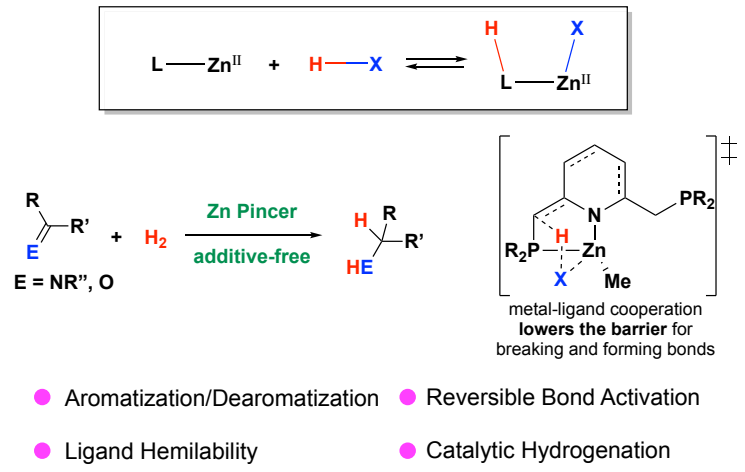

